\title{
ANALISIS MANAJEMEN RISIKO SISTEM INFORMASI PERPUSTAKAAN UNIVERSITAS LAMPUNG MENGGUNAKAN METODE NIST SP 800-30
}

\author{
${ }^{1}$ Danis Sela Valena, ${ }^{2}$ Rizky Prabowo, ${ }^{3}$ Anie Rose Irawati, ${ }^{4}$ Aristoteles \\ 1,2,3,4 Jurusan Ilmu Komputer \\ Fakultas Matematika dan Ilmu Pengetahuan Alam \\ Universitas lampung \\ Jalan soemantri brojonegoro no 1 bandar lampung \\ ${ }^{1}$ danissela13@gmail.com, ${ }^{2}$ Rizky.prabowo@fmipa.unila.ac.id, ${ }^{3}$ b_anie31@yahoo.com, \\ 4aristo_tole@yahoo.com
}

\begin{abstract}
The rapid growth of implementing library information system causing a thrreatening risk. The main cause of the risk is from librarian it self that cannot evaluate which of the factor is a potential threat. This research intend to analyze the risk management of library information system in library of Lampung University, this research using NIST SP 800-30 method. This library information system risk management held for anticipating the source of threat by the following step risk assesment, risk mitigation, and risk evaluation. The result of this risk management is, late book returning, book disspearance, no backup data sejarah of damaged book, theres no matching between data in system and stock in library, data falsisication in borrowing book, redundant data, expired KTM, and lack of understanding when uploading skripsi by scholar. The from risk assesment for late book returning is high risk, to reduce and eliminate the impact of risk library of Lampung University do risk mitigation with early warning. The factor that influencing library information system Lampung University risk assesment is human resource that having and ability in information technology for convenience support to risk all risk in every circumstances.
\end{abstract}

Keywords: Risk Management, Information System, NIST SP 800-30, Library.

\section{Pendahuluan}

Perpustakaan adalah institusi pengelola koleksi karya tulis, karya cetak, atau karya rekam secara profesional dengan sistem yang baku guna memenuhi kebutuhan pendidikan, penelitian, pelestarian, informasi, dan rekreasi para pustakawan.[1]Sifat sistem informasi yang mudah diakses dan digunakan menjadi alasan utama dipilih UPT Perpustakaan Universitas Lampung untuk pelayanan informasi perpustakaan. Sistem informasi perpustakaan telah menjadi bagian yang sulit dipisahkan dalam setiap kegiatan layanan dan proses pengelolaan yang dilakukan oleh perpustakaan. UPT Perpustakaan Universitas Lampung yang merupakan salah satu unit yang sudah menerapkan sistem informasi dalam pelaksanaan kegiatannya, seperti mengurangi kegiatan pelayanan masih sering ditemukan pelayanan yang kurang baik dan lambat dalam pelaksanaan proses yang ada di UPT Perpustakaan Unila. Hal ini terjadi mulai dari proses pencarian buku, peminjaman buku, sampai proses unggah skripsi bagi mahasiswa yang ingin lulus sebagai salah satu persyaratan dalam kelulusan. Hal di atas sudah menerangkan alasan dalam perubahan penggunaan sistem informasi pada UPT Perpustakaan Unila. Tahapan pelayanan yang dilakukan UPT Perpustakaan Universitas Lampung terdapat beberapa kegiatan dimana kegiatan tersebut mulai dari peminjaman, pengembalian, dan unggah skripsi. Dari semua tahapan kegiatan tersebut ditemukan masalah dan menjadi risiko atau ancaman bagi sistem informasi yang ada pada UPT 
Perpustakaan Unila, masalah-masalah tersebut yang akhirnya manjadi sebuah penghambat bagi proses pelayanan kepada mahasiswa yang menggunakan sistem informasi.

Untuk mengetahui proses penerapan manajemen risiko sistem informasi perpustakaan, diperlukan penelitian tentang sejauh mana penerapan manajemen risiko sistem informasi perpustakaan dalam menganalisis, mengurangi, serta mengevaluasi risiko terhadap aset informasi perpustakaan di Perpustakaan Universitas Lampung. Penelitian ini bertujuan untuk mendeskripsikan pelaksanaan manajemen risiko sistem informasi perpustakaan di Perpustakaan Universitas Lampung dalam mengidentifikasi, menganalisis, mengelola evaluasi risiko dengan menggunakan framework NIST SP 800-30 dan untuk mengetahui faktor-faktor apa yang mempengaruhi pelaksanaan manajemen risiko sistem informasi perpustakaan.

\section{Tinjuan Pustaka}

\subsection{Manajemen Risiko}

Manajemen risiko didefinisikan sebagai suatu metode logis dan sistematik dalam identifikasi, kuantifikasi, menentukan sikap, menetapkan solusi, serta melakukan monitor dan pelaporan risiko yang berlangsung pada setiap aktivitas atau proses. [2]

\subsection{Risiko}

Risiko adalah suatu peluang, dampak negatif dari pelaksanaan kerentanan, mempertimbangkan probabilitas dan dampak dari risiko. perusahaan dapat memperkecil risiko dengan melakukan antisipasi berupa kontrol, namun tidak mungkin dapat sepenuhnya menghindari adanya exposure, bahkan dengan struktur pengendalian maksimal sekalipun. [3]

\subsection{Sistem Informasi}

sistem Informasi sebagai kumpulan elemen yang saling berhubungan satu dengan yang lain membentuk satu kesatuan untuk mengintegrasikan data, memproses dan menyimpan serta mendistribusikan informasi [4]

\subsection{Metode NIST SP 800-30}

NIST SP 800-30 adalah dokumen standar yang dikembangkan oleh National Institute of Standards and Technology Special Publication yang mana merupakan kelanjutan dari tanggung jawab hukum di bawah undang-undang Computer Security Act tahun 1987 dan The Information Technology Management Reform Act tahun 1996. NIST mengeluarkan rekomendasi melalui publikasi khusus 800-30 tentang Risk Management Guide for Information Technology System. Terdapat tiga proses dalam manajemen risiko yang dikeluarkan oleh NIST SP 800-30 yaitu penilaian risiko, mitigasi risiko dan evaluasi risiko [5].

\section{Penilaian Risiko (Risk Assesment)}

Merupakan langkah pertama dari metodologi manajemen risiko yang dikeluarkan oleh NIST. Organisasi menggunakan penilaian risiko untuk mendefinisikan ancaman potensial dan risiko yang berhubungan dengan penggunaan teknologi informasi. Output dari proses ini diharapkan membantu mengidentifikasi bagaimana kontrol untuk melakukan pengurangan dan penghilangan risiko selama proses mitigasi. Proses ini terdiri dari 9 (sembilan) langkah yaitu karakteristik sistem, identifikasi ancaman, identifikasi kerentanan, analisis kontrol, penentuan kemungkinan, analisis dampak, penentuan risiko, rekomendasi kontrol, dan hasil dokumentasi. 


\section{Peringanan Risiko (Risk Mitigation)}

Merupakan tahap kedua dari proses manajemen risiko yang dikeluarkan NIST melibatkan prioritasisasi, evaluasi dan implementasi rekomendasi dari kontrol pengurangan risiko dari tahapan sebelumnya yaitu penilaian risiko. Pengurangan atau biasa lebih dikenal dengan mitigasi merupakan metodologi sistemik yang digunakan manajemen untuk mengurangi dampak risiko. Terdapat tujuh langkah dalam tahap ini yaitu prioritas aksi, opsi evaluasi rekomendasi kontrol, aturan analisis akibat dan biaya, pemilihan kontrol, tugas dan tanggungjawab, pengembangan rencana perlindungan, dan implementasi kontrol.

\section{Evaluasi Risiko (Risk Evaluation)}

Kegiatan evaluasi risiko adalah kegiatan terhadap keberlangsungan proses peringanan, pada umumnya jaringan yang diterapkan dalam organisasi akan mengalami perubahan atau pengembangan komponen hardware, pengembangan software dan aplikasi oleh versi yang lebih up to date dan lebih baru.

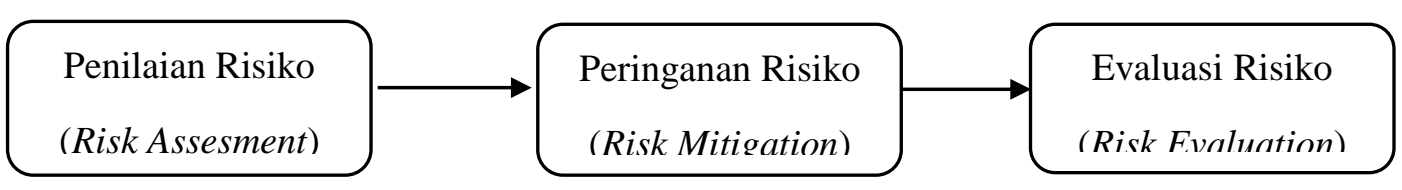

Gambar 1. Metode NIST SP 800-30 [6]

\section{Metodologi}

\subsection{Pengumpulan Data}

Adapun data-data yang dikumpulkan pada saat melakukan tahap perencanaan adalah sebagai berikut:

1. Data primer

Data primer adalah data yang secara langsung diambil dari sumber aslinya. Melalui narasumber yang tepat dan dapat dijadikan sumber informasi dalam proses penilaian resiko sistem informasi Perpustakaan Universitas Lampung. Adapun data primer yang didapat yaitu: Hasil observasi dan wawancara mengenai resiko yang pernah terjadi pada Perpustakaan Universitas Lampung.

2. Data sekunder

Data sekunder adalah data yang sudah tersedia di instansi. Adapun data yang diperoleh adalah data seperti buku, jurnal, dan informasi dari internet yang berhubungan dengan menejemen resiko.

\subsection{Tahap Pengumpulan Data}

Pada tahap ini, merupakan tahap pengumpulan data untuk menghasilkan data sebagai hipotesis awal dari proses analisis resiko yang akan dilakukan. Pada tahap ini penulis melakukan pengumpulkan data selama penelitian dilakukan. Dalam pengumpulan data penulis melakukan beberapa teknik untuk mendapatkan data. Adapun teknik dan data yang dikumpulkan adalah sebagai berikut:

\section{Observasi}

Observasi ini dilakukan untuk mengamati keadaan sesuai dengan topik yang akan dibahas. Pada tahap ini, dilakukan survey secara langsung dengan mengunjungi Perpustakaan Unviersitas Lampung untuk melihat dan mengamati teknologi sistem informasi yang digunakan, resiko yang pernah dialami dan bagaimana proses yang dijalankan pihak menejemen resiko Perpustakaan dalam mendukung proses bisnis yang berjalan.

\section{Wawancara}

Tahap wawancara dilakukan di bagian IT Perpustakaan Universitas Lampung, yang bertujuan untuk mengetahui masalah dan resiko yang pernah dialami. 
Pengumpulan data lapangan terlebih dahulu dengan melaksanakan observasi pendahuluan tentang tema kajian yang diteliti untuk lebih mendalami kajian yang akan diteliti. Wawancara dilaksanakan tanpa interupsi, sehingga informan mengutarakan pengalamannya secara khusus, mendetail dengan terlebih dahulu mendengarkan pertanyaan wawancara dari peneliti. Apabila ada pengungkapan pendapat yang tidak sesuai dengan tema, maka peneliti memfokuskan pada tema pokok kajian penelitian.

\section{Pembahasan}

\subsection{Hasil Penelitian}

Berdasarkan hasil riset dalam pelaksanaan penelitian ini, peneliti mendapatkan hasil resiko yang didapatkan dari UPT Perpustakaan dengan hasil wawancara, seperti yang dijelaskan diatas sebelumnya, dengan tahapan NIST SP 800-30 yang sebelumnya disebutkan maka peneliti mendapatkan resiko yang mengancam UPT Perpustakaan Universitas Lampung, resiko yang didapatkan oleh peneliti juga sudah mencakup dengan karakteristik dari setiap resiko dengan hasil akhirnya adalah mengklasifikasikan resiko menjadi resiko dengan tingkat high (tingggi), medium (sedang), dan low (rendah).

\subsubsection{Penilaian Risiko}

Berdasarkan hasil wawancara yang dilakukan pada UPT Perpustakaan Universitas Lampung, didapatkan hasil dalam Penilaian Risiko yang digunakan untuk mengidentifikasi dan mengklasifikasikannya. Proses penilaian risiko (risk assessment) dilakukan dengan beberapa tahapan, sesuai dengan kerangka kerja NIST SP800-30. Tahapan-tahapan tersebut sebagai berikut:

1. Risk Assesment (Karakteristik Sistem)

Karakteristik sistem yang meliputi sistem informasi, diantaranya perangkat keras, perangkat lunak, data dan informasi, dan sumber daya manusia yang mendukung sistem informasi. Sumber daya perangkat keras meliputi PC yang digunakan untuk server dengan sistem operasi Linux Ubuntu. Sedangkan perangkat lunak pada server menggunakan SQL Server dan Apache Server. Data dan informasi meliputi data masukan yaitu mahasiswa, peminjaman, pengembalian, dan buku yang tersedia. Sumber daya manusia terdiri dari operator bidang dan sistem.

2. Threat Identification (Identifikasi Ancaman)

Berdasarkan hasil wawancara dan observasi lapangan, identifikasi ancaman yang menghambat pelayanan UPT Perpustakaan Universitas Lampung dapat dilihat pada Tabel 1.

Tabel 1 Identifikasi Ancaman

\begin{tabular}{cl}
\hline No & \multicolumn{1}{c}{ Risiko } \\
\hline 1 & Keterlambatan Pengembalian Buku \\
\hline 2 & Buku hilang \\
\hline 3 & Tidak ada backup data sejarah buku rusak \\
\hline 4 & Ketidaksesuaian data pada stok di sistem dan stok fisik \\
\hline 5 & Pemalsuan data dalam peminjaman buku \\
\hline 6 & Redundant data \\
\hline 7 & KTM Kadaluarsa \\
\hline 8 & Ketidak pahaman mahasiswa cara unggah skripsi \\
\hline
\end{tabular}


3. Vulnerability Identification (Identifikasi Kerentanan)

Kerentanan yang teridentifikasi meliputi kesalahan manusia (human error) yang berdampak pada sistem informasi seperti halnya terjadi beberapa risiko yaitu redundant data, hal ini terjadi karena kesalahan dalam memasukkan data buku yang dimiliki perpustakaan dan diunggah ke aplikasi sistem namun terjadi kesalahan sehingga risiko tersebut dapat terjadi.

4. Control Analysis (Analisa Kontrol)

Analisa kontrol secara khusus untuk kegiatan penilaian risiko belum terdokumentasi, tetapi hanya berdasarkan pada pengetahuan dan kesadaran dari pustakawan dalam mengenali, mendeteksi dan melaksanakan tindakan pencegahan terhadap risiko yang mengancam seperti yang dapat dilihat pada Tabel 2.

Tabel 2 Analisa Kontrol

\begin{tabular}{|c|c|}
\hline Resiko & Analisa Kontrol \\
\hline $\begin{array}{l}\text { Keterlambatan Pengembalian } \\
\text { Buku }\end{array}$ & $\begin{array}{l}\text { Peringatan melalui layanan di web UPT } \\
\text { Perpustakaan untuk memberitahukan } \\
\text { kepada seluruh mahasiswa dalam } \\
\text { keterlambatan pengembalian buku }\end{array}$ \\
\hline Buku hilang & $\begin{array}{l}\text { Memberi sanksi dengan mengganti satu } \\
\text { buku seperti yang dihilangkan }\end{array}$ \\
\hline $\begin{array}{l}\text { Tidak ada backup data sejarah } \\
\text { buku rusak }\end{array}$ & $\begin{array}{l}\text { Sosialisasi pemberitahuan untuk menjaga } \\
\text { buku }\end{array}$ \\
\hline $\begin{array}{l}\text { Ketidaksesuaian data pada stok di } \\
\text { sistem dan stok fisik }\end{array}$ & maintenance data dalam periode tertentu \\
\hline $\begin{array}{l}\text { Pemalsuan data dalam } \\
\text { peminjaman buku }\end{array}$ & $\begin{array}{l}\text { Melakukan pemeriksaan KTM kembali } \\
\text { sebelum peminjaman buku }\end{array}$ \\
\hline Redundant data buku & $\begin{array}{l}\text { filter pada sistem pencarian buku untuk } \\
\text { penghapusan data buku yang ganda }\end{array}$ \\
\hline KTM Kadaluarsa & $\begin{array}{l}\text { Perpanjang KTM melalui petugas } \\
\text { peminjaman }\end{array}$ \\
\hline $\begin{array}{l}\text { Ketidak pahaman mahasiswa cara } \\
\text { unggah skripsi }\end{array}$ & $\begin{array}{l}\text { Memberikan format detail upload skripsi di } \\
\text { web }\end{array}$ \\
\hline
\end{tabular}

5. Likelihood Determination (Kemungkinan yang Menentukan)

Hasil dari analisis kontrol dijadikan sebagai bahan acuan dalam penentuan kemungkinan risiko. Penentuan kemungkinan ini untuk menentukan besaran tingkat kemungkinan yang akan terjadi terhadap risiko yang telah teridentifikasi. Tingkat kemungkinan terbagi menjadi tiga kategori yaitu 1. Tinggi, sumber ancaman yang memiliki motivasi tinggi yang dapat merugikan organisasi, hal ini terjadi karena pengendalian untuk mencegah kerentanan dilakukan tidak efektif. 2. Sedang, sumber ancaman memiliki motivasi yang mampu merugikan organisasi, tetapi organisasi masih dapat melakukan kontrol yang mana mampu menghambat keberhasilan dari kerentanan yang ada. 3. Rendah, sumber ancaman yang memiliki motivasi kurang atau rendah, kontrol digunakan untuk mencegah atau mengurangi suatu kerentanan yang akan terjadi pada organisasi.

Hasil dari kemungkinan risiko yang menentukan dapat dilihat pada Tabel 3. 
Tabel 3 Kemungkinan yang Menentukan

\begin{tabular}{ll}
\hline \multicolumn{1}{c}{ Risiko } & Nilai Dampak \\
\hline Keterlambatan Pengembalian Buku & High \\
\hline Buku hilang & Medium \\
\hline Tidak ada backup data sejarah buku rusak & Medium \\
\hline $\begin{array}{l}\text { Ketidaksesuaian data pada stok di sistem dan stok } \\
\text { fisik }\end{array}$ & Medium \\
\hline Pemalsuan data dalam peminjaman buku & Medium \\
\hline Redundant data & Low \\
\hline KTM Kadaluarsa & Low \\
\hline Ketidak pahaman mahasiswa cara unggah skripsi & Low \\
\hline
\end{tabular}

6. Impact Analysis (Analisa Dampak)

Berdasarkan kemungkinan risiko yang dapat mengancam keberlangsungan sistem informasi, maka dampak risikonya dapat dilihat pada Tabel 4.

Tabel 4 Dampak Risiko pada Sistem Informasi Perpustakaan Universitas Lampung

\begin{tabular}{lll}
\hline Risiko & \multicolumn{1}{c}{ Dampak Risiko } & Nilai Dampak \\
\hline $\begin{array}{l}\text { Keterlambatan } \\
\text { pengembalian buku }\end{array}$ & $\begin{array}{l}\text { a. } \\
\text { b. } \begin{array}{l}\text { Mahasiswa mendapatkan } \\
\text { Mahasiswa sulit untuk } \\
\text { bebas perpustakaan }\end{array}\end{array}$ & High \\
\hline Buku hilang & $\begin{array}{l}\text { Tidak adanya alternatif } \\
\text { untuk menjamin buku yang } \\
\text { hilang dari mahasiswa } \\
\text { b. Mendata ulang buku }\end{array}$ & Medium \\
\hline $\begin{array}{l}\text { Tidak ada backup } \\
\text { data sejarah buku } \\
\text { rusak }\end{array}$ & $\begin{array}{l}\text { Jika terjadi kerusakan pada } \\
\text { buku tidak tahu pelakuknya }\end{array}$ & Medium \\
\hline $\begin{array}{l}\text { Ketidaksesuaian } \\
\text { data pada stok di } \\
\text { sistem dan stok fisik }\end{array}$ & $\begin{array}{l}\text { Tidak adanya keterangan } \\
\text { jumlah buku yang dipinjam } \\
\text { dan sisa buku yang dipinjam }\end{array}$ & Medium \\
\hline $\begin{array}{l}\text { Pemalsuan data } \\
\text { dalam } \\
\text { peminjaman buku }\end{array}$ & $\begin{array}{l}\text { Mengakibatkan kerugian } \\
\text { pada pemilik KTM asli }\end{array}$ & Medium \\
\hline $\begin{array}{l}\text { Redundant data } \\
\text { Ketidak pahaman }\end{array}$ & $\begin{array}{l}\text { Ditemukan data double } \\
\text { untuk buku yang berjudul } \\
\text { sama }\end{array}$ & Low \\
\hline $\begin{array}{l}\text { Mahasiswa tidak dapat } \\
\text { memingam buku melalui }\end{array}$ & Low \\
\hline $\begin{array}{l}\text { Tidak adanya format baku } \\
\text { dalam sistem tentang } \\
\text { langkah penguploadan } \\
\text { skripsi }\end{array}$ & Low \\
\hline
\end{tabular}


7. Risk Determination (Penentuan Risiko)

Penentuan risiko ini bertujuan untuk menilai tingkat risiko terhadap sistem, untuk menilai tingkat risiko ini mengacu kepada kemungkinan risiko dan dampak risiko yang sudah ditentukan. Penentuan risiko dapat dilihat pada Tabel 5.

Tabel 5 Penentuan Risiko pada Sistem Informasi Perpustakaan Universitas Lampung

\begin{tabular}{lcccc}
\hline \multicolumn{1}{c}{ Risiko } & $\begin{array}{c}\text { Nilai } \\
\text { Kemungkinan }\end{array}$ & $\begin{array}{c}\text { Nilai } \\
\text { Dampak }\end{array}$ & $\begin{array}{c}\text { Nilai } \\
\text { Risiko }\end{array}$ & $\begin{array}{c}\text { Tingkat } \\
\text { Risiko }\end{array}$ \\
\hline $\begin{array}{l}\text { Keterlambatan } \\
\text { pengembalian buku }\end{array}$ & 1.0 & 100 & 100 & High \\
\hline Buku hilang & 0.5 & 100 & 50 & Medium \\
\hline $\begin{array}{l}\text { Tidak ada backup } \\
\text { data sejarah buku } \\
\text { rusak }\end{array}$ & 0.5 & 50 & 25 & Medium \\
\hline $\begin{array}{l}\text { Ketidaksesuaian } \\
\text { data pada stok di } \\
\text { sistem dan stok fisik }\end{array}$ & 0.5 & 100 & 50 & Medium \\
\hline $\begin{array}{l}\text { Pemalsuan data } \\
\text { dalam peminjaman } \\
\text { buku }\end{array}$ & 0.5 & 50 & 25 & Medium \\
\hline Redundant data & 0.5 & 10 & 5 & Low \\
\hline $\begin{array}{l}\text { KTM kadaluarsa } \\
\text { Ketidak pahaman } \\
\text { mahasiswa cara } \\
\text { unggah skripsi }\end{array}$ & 0.5 & 10 & 5 & Low \\
\hline
\end{tabular}

8. Control Rekomendations (Rekomendasi Kontrol)

Dalam tahap ini bertujuannya untuk mengurangi level risiko pada sistem informasi Perpustakaan Universitas Lampung. Rekomendasi Kontrol dapat dilihat dalam Tabel 6.

Tabel 6 Rekomendasi Kontrol Risiko pada Sistem Informasi Perpustakaan Universitas Lampung

\begin{tabular}{lcl}
\hline \multicolumn{1}{c}{ Resiko } & $\begin{array}{c}\text { Tingkat } \\
\text { Risiko }\end{array}$ & \multicolumn{1}{c}{ Rekomendasi } \\
\hline $\begin{array}{l}\text { Keterlambatan } \\
\text { Pengembalian } \\
\text { Buku }\end{array}$ & High & $\begin{array}{l}\text { Early warning operator untuk mengingatkan } \\
\text { mahasiswa yang meminjam buku. }\end{array}$ \\
\hline Buku hilang & Medium & $\begin{array}{l}\text { a. Mengganti dua buah buku yang sama dengan buku } \\
\text { yang telah dihilangkan } \\
\text { b.Memberi denda yang besar seperti tiga kali lipat } \\
\text { harga buku }\end{array}$ \\
\hline
\end{tabular}




\begin{tabular}{|c|c|c|}
\hline Resiko & $\begin{array}{c}\text { Tingkat } \\
\text { Risiko }\end{array}$ & Rekomendasi \\
\hline & & $\begin{array}{l}\text { c. Memasang chip seperti GPS untuk mengetahui } \\
\text { lokasi buku tersebut }\end{array}$ \\
\hline $\begin{array}{l}\text { Tidak ada backup } \\
\text { data sejarah buku } \\
\text { rusak }\end{array}$ & Medium & $\begin{array}{l}\text { Pada saat pengembalian petugas UPT Perpustakaan } \\
\text { harus mengecek dengan benar dan teliti atau dengan } \\
\text { penambahan sistem untuk mendeteksi bentuk fisik } \\
\text { buku. }\end{array}$ \\
\hline $\begin{array}{l}\text { Ketidaksesuaian } \\
\text { data pada stok di } \\
\text { sistem dan stok } \\
\text { fisik }\end{array}$ & Medium & $\begin{array}{l}\text { UPT Perpustakaan mendata ulang dan meng cross } \\
\text { check kembali stock buku dan yang ada di sistem. }\end{array}$ \\
\hline $\begin{array}{l}\text { Pemalsuan data } \\
\text { dalam peminjaman } \\
\text { buku }\end{array}$ & Medium & $\begin{array}{l}\text { Sebelum mahasiswa melakukan registrasi kartu } \\
\text { keanggotaan perpustakaan mahasiswa harus } \\
\text { melakukan finger print recording dan face recording }\end{array}$ \\
\hline Redundant data & Low & $\begin{array}{l}\text { Perlu melakukan filter pada sistem pencarian buku } \\
\text { untuk penghapusan data buku yang double }\end{array}$ \\
\hline KTM Kadaluarsa & Low & $\begin{array}{l}\text { Perbaikan atau maintenance dari UPT Perpustakaan } \\
\text { untuk melakukan penyederhaan tahapan pelayanan } \\
\text { perpanjangan KTM }\end{array}$ \\
\hline $\begin{array}{l}\text { Ketidak pahaman } \\
\text { mahasiswa cara } \\
\text { unggah skripsi }\end{array}$ & Low & $\begin{array}{l}\text { Evaluasi ke sistem dengan memaparkan secara } \\
\text { detail panduan untuk upload skripsi agar setiap } \\
\text { mahasiswa tidak harus upload ulang karena } \\
\text { kesalahan format }\end{array}$ \\
\hline
\end{tabular}

9. Result Documentation (Dokumentasi Hasil)

Hasil dari penilaian risiko didokumentasikan berupa profil risiko yang dapat mengancam keberlangsungan sistem informasi, dan solusi pencegahan melalui rekomendasi kontrol sebagai tindak lanjut proses berikutnya melalui kegiatan peringanan risiko.

\subsubsection{Peringanan Risiko}

Setelah dianalisis pada tahap penilaian risiko maka didapatkan profil risiko dengan berbagai proses rekomendasi pemecahan yang sekiranya dapat digunakan dalam proses peringanan risiko yang sesuai dengan kebutuhan di Perpustakaan Universitas Lampung. Dimana risiko yang memiliki tingkat tertinggi yang harus dijadikan sebagai prioritas utama dalam proses peringanan risiko. Dalam kegiatan peringanan risiko diperlukan tahapan proses yang meliputi berbagai kegiatan secara bertahap dan berkelanjutan seperti pada Tabel 7.

Tabel 7 Peringanan Risiko

\begin{tabular}{ll}
\hline & \multicolumn{1}{c}{ Keterlambatan Pengembalian Buku } \\
\hline Prioritas Aksi & $\begin{array}{l}\text { Early warning operator untuk mengingatkan mahasiswa yang } \\
\text { meminjam buku. }\end{array}$ \\
\hline $\begin{array}{l}\text { Opsi Evaluasi } \\
\text { Rekomendasi } \\
\text { Kontrol }\end{array}$ & $\begin{array}{l}\text { Broadcast ke masing-masing mahasiswa dalam bentuk e-mail, media } \\
\text { sosial seperti facebook, whatsapp dan lain-lain. }\end{array}$ \\
\hline $\begin{array}{l}\text { Aturan Analisis } \\
\text { Akibat dan Biaya }\end{array}$ & $\begin{array}{l}\text { Dilakukannya sosialisasi tentang sanksi dari akibat keterlembatan } \\
\text { pengembalian buku. Biaya tambahan untuk tenaga IT dalam proses } \\
\text { pengembangan sistem agar mengurangi dampak risiko yang terjadi. }\end{array}$ \\
\hline
\end{tabular}




\begin{tabular}{ll}
\hline $\begin{array}{l}\text { Pemilihan } \\
\text { Kontrol }\end{array}$ & $\begin{array}{l}\text { Peringatan dini yang dilakukan harus diklasifikasikan dengan } \\
\text { beberapa tindakan berdasarkan jumlah hari sebelum berakhirnya } \\
\text { batas pengembalian buku. }\end{array}$ \\
\hline Tugas dan & $\begin{array}{l}\text { Pembagian tugas dan tanggung jawab sagat penting untuk } \\
\text { Tanggungjawab } \\
\text { memfokuskan kegiatan agar meningkatkan kinerja kerja pada staf, } \\
\text { ketika terjadi penumpukkan pekerjaan, maka akan terjadi tumpang } \\
\text { tindih dan tidak fokusnya pekerjaan dan tanggung jawab yang sudah } \\
\text { dibagi atau di distribusikan. }\end{array}$ \\
\hline Pengembangan & $\begin{array}{l}\text { Kegiatan dimulai dengan mengklasifikasikan jumlah hari yang dibagi } \\
\text { untuk melakukan tahapan early warning, penguatan data mahasiswa }\end{array}$ \\
& $\begin{array}{l}\text { yang berfungsi untuk tercapainya peringatan secara langsung kepada } \\
\text { mahasiswa, hal ini bisa dimulai dengan data data pribadi untuk } \\
\text { dihubungi. }\end{array}$ \\
\hline Kmplementasi & $\begin{array}{l}\text { Kegiatan peringatan dini (early warning) seperti adanya pengingat } \\
\text { bagi petugas UPT Perpustakaan untuk mengingatkan peminjam buku } \\
\text { Kontrol }\end{array}$ \\
atau mahasiswa untuk segera mengembalikan buku agar tidak \\
terjadinya keterlambatan
\end{tabular}

\subsubsection{Evaluasi Risiko}

Evaluasi risiko merupakan tahap akhir dalam proses manajemen risiko sistem informasi perpustakaan dengan menggunakan framework NIST Special Pu blication 800-30. Keterlambatan pengembalian buku dapat diatasi dengan kegiatan peringatan dini (early warning) seperti adanya pengingat bagi petugas UPT Perpustakaan peminjam buku atau mahasiswa untuk segera mengembalikan buku agar tidak terjadinya keterlambatan atau dengan broadcast ke masingmasing mahasiswa dalam bentuk e-mail, media sosial seperti facebook, whatsapp dan lain-lain dengan dilakukannya sosialisasi tentang sanksi dari akibat keterlembatan pengembalian buku. Biaya tambahan untuk tenaga IT dalam proses pengembangan sistem agar mengurangi dampak risiko yang terjadi. Pembagian tugas dan tanggung jawab sagat penting untuk memfokuskan kegiatan agar meningkatkan kinerja kerja pada staf, ketika terjadi penumpukkan pekerjaan, maka akan terjadi tumpang tindih dan tidak fokusnya pekerjaan dan tanggung jawab yang sudah ditetapkan. Kegiatan dimulai dengan mengklasifikasikan jumlah hari yang dibagi untuk melakukan tahapan early warning, penguatan data mahasiswa yang berfungsi untuk tercapainya peringatan secara langsung kepada mahasiswa, hal ini bisa dimulai dengan data data pribadi untuk dihubungi.

\section{Kesimpulan}

Berdasarkan hasil penelitian yang telah dilaksanakan maka diperoleh kesimpulan berikut:

1. Proses penilaian risiko (risk assessment) mendeskripsikan profil risiko yang mengancam sistem informasi perpustakaan berdasarkan rangking level risiko meliputi keterlambatan pengembalian buku dengan level risiko tinggi, buku hilang dengan level risiko sedang, tidak ada backup data sejarah buku rusak dengan level risiko sedang, ketidaksesuaian data yang ada disistem dengan keadaan (stoknya) dengan level risiko sedang, dan pinjam meminjam KTM orang lain dengan level risiko sedang.

2. Proses peringanan risiko yang dilakukan pihak UPT Perpustakaan Universitas Lampung dengan mengimplementasikan sistem early warning untuk monitoring agar tidak terjadi keterlambatan dalam pengembalian buku. 
3. Evaluasi kegiatan manajemen risiko sistem informasi UPT Perpustakaan Universitas Lampung belum dilaksanakan sesuai prosedur yang sudah ditetapkan. Untuk menghindari ancaman yang dapat menimbulkan risiko terhadap sistem informasi baru dilaksanakan secara rutin proses backup data saja. Adapun yang perlu diperhatikan adalah dengan melakukan kebijakankebijakan yang menunjang untuk perbaikan pelayanan yang diberikan oleh pihak UPT Perpustakaan agar dapat memberikan pelayanan secara maksimal, hal ini guna meringankan resiko dimana jika terjadi pengulangan risiko dengan jumlah pengulangan yang terlalu sering maka tidak hanya akan merugikan pihak univerrsitas, namun juga akan berpengaruh pada kerugian UPT Perpustakaan karena harus selalu mengalami kerugian.

4. Manajemen risiko dengan menggunakan kerangka kerja NIST SP 300-80, dapat mendeskripsikan profil risiko yang dapat mengancam keberlangsungan sistem informasi pada sebuah organisasi yang memiliki dan menggunakan sistem informasi sebagai sebuah bentuk inovasi dalam setiap kegiatannya.

\section{Referensi}

[1] N. 43, "UNDANG-UNDANG REPUBLIK INDONESIA TENTANG PERPUSTAKAAN," Jakarta, 2007.

[2] F. N. Idroes, Manajemen Risiko perbankan: Pemahaman Pendektan 3 pilar Kesepakatan Bassel II Terkait Aplikasi Regulasi dan Pelaksanaannya di Indonesia, Jakarta: Rajawali Pers, 2008.

[3] J. H. Pinontoan, "Manajemen Risiko TI Konsep-konsep," Majalah PC Media, 2010.

[4] B. S. D. Oetomo, Perencanaan dan Pembangunan Sistem Informasi, yogyakarta: Andi, 2002.

[5] J. Wolingpirayat, "E-payment Strategies of Bank Card Innovation," Journal of Internet Banking And Commerce, 2007.

[6] U. Nugraha, Manajemen Risiko Sistem Informasi Pada Perguruan Tinggi Menggunakan Kerangka Kerja NIST SP 800-30, Bandung: SELISIK, 2016. 